\title{
Avaliação de geleia de tamarindo sem pectina e com pectina proveniente do albedo do maracujá amarelo
}

\section{Evaluation of tamarind jelly without pectin and pectin from the albedo of yellow passion fruit}

\author{
Florisvaldo Gama de SOUZA ${ }^{[1, *]}$ (D), Fabrízio da Fonseca BARBOSA ${ }^{[2]}$ (D) e Fernando Morais \\ RODRIGUES ${ }^{[1]}[10$
}

[1] Instituto Federal de Educação, Ciência e Tecnologia do Tocantins, Campus Paraíso, Rodovia BR 153, Km 480, Distrito Industrial, Paraíso do Tocantins, TO, Brasil. CEP: 77600-000, Brasil. fernandomorais@ifto.edu.br

[2] Universidade Federal de Pelotas, Centro de Ciências, Químicas, Farmacêuticas e de Alimentos, Campus Universitário - Capão do Leão, Caixa Postal:354, Pelotas, RS, Brasil. CEP: 96010-900, Brasil. fabriziobarbosa@yahoo.com.br

*Autor para correspondência: florisvaldo@ifto.edu.br

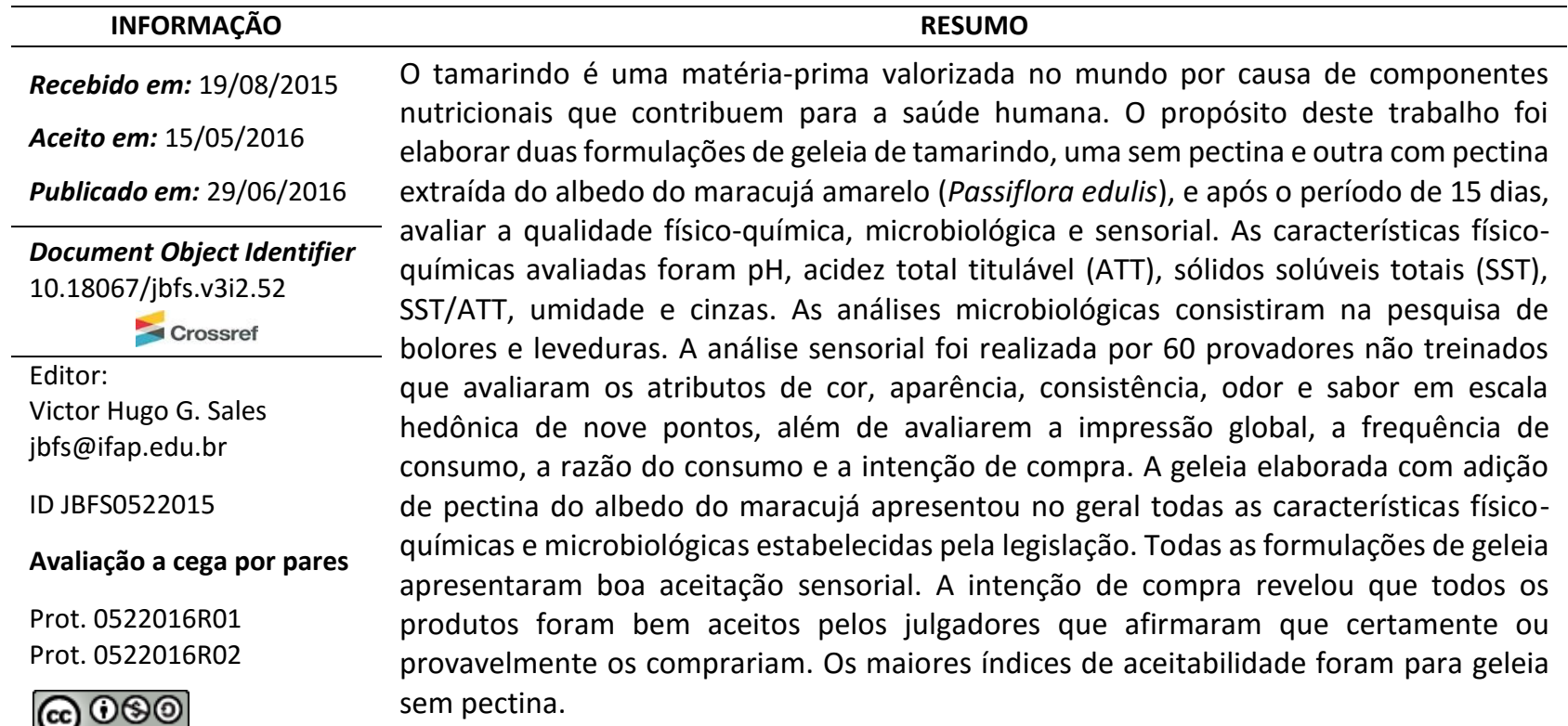

NO SA JBFS all rights

Copyright: (C) 2016
Palavras-chave: Processamento, Tamarindus indica, Passiflora edulis

ABSTRACT - The tamarind is a raw material valued in the world due to its nutritional components that contribute to their healthy characteristics. The purpose of this work was to develop two formulations of tamarind, a jelly without pectin and another with pectin extracted from the albedo of yellow passion fruit (Passiflora edulis), and after the period of 15 days evaluate the physical and chemical quality, microbiological and sensory. The physicochemical characteristics evaluated were $\mathrm{pH}$, titratable total acidity (ATT), total soluble solids (TSS), SST/ATT, moisture and ash. The microbiological analysis consisted in the research of molds and yeasts. Sensory analysis was performed for 60 untrained tasters that evaluated the attributes of color, appearance, consistency, smell and taste in hedonic scale of nine points, and assessed the overall impression, the frequency of consumption, the ratio of consumption, and buy intention. The jelly prepared with pectin addition of passion fruit albedo presented in general all the physicochemical and microbiological characteristics established by law. All jelly formulations showed good sensory acceptance. The intention to purchase revealed that all products have been well accepted by the judges, who said they definitely or probably buy. The highest acceptability rates were to jam without pectin.

Keywords: Processing, Tamarindus indica, Passiflora edulis

Financiamento: Os autores reportam que não houve suporte e auxílio financeiro.

Conflito de interesse: Os autores declaram que não há conflito de interesse.

Como citar esse documento (ABNT):

SOUZA, F.G.; BARBOSA, F.F.; RODRIGUES, F.M. Avaliação de geleia de tamarindo sem pectina e com pectina proveniente do albedo do maracujá amarelo. Journal of Bioenergy and Food Science, v.3, n.2, p.78-88, 2016. DOI:10.18067/jbfs.v3i2.52 


\section{INTRODUÇÃO}

O Cerrado, segundo maior bioma do Brasil, apresenta uma rica biodiversidade vegetal que possui elevado potencial econômico, nutricional e tecnológico. Entre as espécies presentes do Cerrado, destaca-se o tamarindo (Tamarindus indica L.), nativa da África Tropical, pertencente à família Fabaceae, e frequentemente encontrada em regiões de clima tropical e subtropical no Brasil. ${ }^{1}$

É uma árvore frutífera e bastante decorativa, podendo chegar aos $25 \mathrm{~m}$ de altura. Seu fruto é uma vagem alongada, com 5 a $15 \mathrm{~cm}$ de comprimento, com casca pardo-escura, lenhosa e quebradiça, contendo 3 a 8 sementes envolvidas por uma polpa parda e ácida. Por apresentar sistema radicular profundo, possui resistência a secas prolongadas e, desta forma, é indicada para cultivo em regiões semiáridas. ${ }^{2}$

O tamarindo é uma matéria-prima valorizada no mundo por causa de seus componentes nutricionais que contribuem para a saúde humana. O seu fruto apresenta significativo nível de vitaminas $C, E$ e do complexo $B$, além de cálcio, ferro, fósforo, potássio, manganês e fibra dietética. Há também compostos orgânicos que o tornam um poderoso antioxidante e um agente antiinflamatório. ${ }^{3}$

Pode ser usado para acelerar a função dos intestinos, atuando como laxante suave. A polpa desidratada é um dos melhores purificadores de sangue. É considerado de grande utilidade para corrigir distúrbios biliares, já que sua acidez natural excita a produção da bílis. Se ingerido com frequência, baixa o nível do colesterol, e restaura o bom funcionamento do coração. Para dores de garganta, recomenda-se gargarejo com a polpa diluída em água, sendo que, ainda, reverte a deficiência de Vitamina $C$ no organismo. ${ }^{4}$

O tamarindo é rico em antioxidantes, protegendo as células e mantendo o corpo saudável. Além das condições descritas acima, trata cólicas, sensibilidade ao frio, conjuntivite, disenteria grave, gengivite, paralisia, inchaço na córnea, reduz a dor provocada pela artrite e pela artrose, elimina vômitos e as náuseas durante a gravidez, estimula produção de saliva, ameniza os feitos da insolação sendo que é um protetor solar natural potente, acelera a cicatrização de feridas, reduz dores em geral no corpo. ${ }^{5}$
A comercialização de frutas pelos agricultores familiares é geralmente realizada de forma in natura, no entanto, grande parte da produção é desperdiçada e outra parte é vendida nas feiras livres. A comercialização in natura não é suficiente para a sustentação das atividades da produção agropecuária, dessa forma utilizam-se da prática do processamento agroindustrial para desenvolver produtos com maior valor agregado, tais como: doces, sorvetes, licores, tortas, balas, sucos concentrados, picolé, frutas desidratadas, compotas e geleias, contribuindo com o aumento da renda das famílias. $^{2,6-9}$

Geleia de fruta é o produto obtido pela cocção de frutas inteiras ou em pedaços, polpa ou suco de fruta, com açúcar e água, e concentrado até a consistência gelatinosa. Poderá sofrer a adição de glicose ou açúcar invertido, porém não poderá ser colorida nem aromatizada artificialmente. Além disso, será tolerada a adição de acidulantes e de pectina para compensar qualquer deficiência do conteúdo natural de pectina ou de acidez da fruta. ${ }^{10,11}$

A pectina constitui o elemento fundamental necessário à formação de gel, e deve ser adicionada quando a fruta não é suficientemente rica nesse componente. Segundo a Resolução ANVISA/MS RDC $n^{\circ} 45$, de $2010,{ }^{12}$ a pectina é um aditivo utilizado segundo as Boas Práticas de Fabricação (BPF) que tem a função tecnológica de "espessante". A quantidade de uso da pectina será quantum satis, ou seja, quantidade suficiente para obter o efeito desejado, desde que seu uso não resulte em prática enganosa e a sua adição seja permitida para o alimento em questão. Não é feita restrição quanto ao tipo de pectina.

Todos os alimentos, independentemente de sua origem, podem apresentar uma microbiota natural extremamente variável, concentrada principalmente na região superficial, embora os tecidos internos, tanto de vegetais como de animais, possam eventualmente, apresentar formas microbianas viáveis. As frutas com atividade de água (Aa) maior que 0,98 são muito susceptíveis à deterioração por bactérias, bolores ou leveduras. 0 desenvolvimento e o metabolismo microbiano exigem a presença de água numa forma disponível e a Aa é um índice desta disponibilidade para utilização em reações químicas e multiplicação microbiana. ${ }^{13}$ Contudo, na geleia, o açúcar presente diminui sua atividade de água conservando o 
produto e prolongando sua vida útil de prateleira, por criar condições desfavoráveis de crescimento e multiplicação para a maioria daqueles microrganismos citados anteriormente. ${ }^{14}$

De acordo com Franco e Landgraf ${ }^{15}$ e Gomes e Oliveira, ${ }^{16}$ entre os parâmetros mais importantes que determinam a qualidade de um alimento, sem dúvida, estão aqueles que definem as suas características físico-químicas e microbiológicas, o que permite avaliá-lo quanto às informações qualitativas e quantitativas dos nutrientes presentes nos alimentos, além das condições de processamento, armazenamento, distribuição para consumo, vida útil e riscos à saúde da população.

Ao se desenvolver um novo produto, é imprescindível aperfeiçoar parâmetros, como forma, cor, aparência, odor, sabor, textura, consistência e a interação dos diferentes componentes, com o objetivo final de alcançar um equilíbrio integral e, consequentemente, boa qualidade e aceitabilidade do produto. As percepções sensoriais dos alimentos são interações complexas que envolvem cinco sentidos: visão, olfato, paladar, tato e audição; logo, a avaliação sensorial tem por objetivo detectar diferenças nos produtos avaliados, de acordo com as diferenças perceptíveis na intensidade de alguns atributos. ${ }^{17,} 18$

Diante do exposto, o trabalho teve como objetivo elaborar duas formulações de geleia de tamarindo: uma sem pectina e outra com solução de pectina extraída do albedo do maracujá amarelo e avaliar a qualidade físico-química, microbiológica e sensorial após o período de 15 dias.

\section{MATERIAL E MÉTODOS}

\section{A) Preparo das amostras de geleia}

O processamento da geleia de tamarindo foi realizado na Unidade de Hortifrutigranjeiros do Instituto Federal de Educação, Ciência, Tecnologia do Tocantins, Campus Paraíso do Tocantins. As análises físico-químicas e microbiológicas no Laboratório de Análises de Alimentos e a avaliação sensorial no Laboratório de Análise Sensorial, ambos localizados no Instituto Federal de Educação, Ciência, Tecnologia do Tocantins, Campus Paraíso do Tocantins.

As matérias-primas para realização do experimento foram adquiridas de um pomar na Vila de Santana, na Cidade de Paraíso do Tocantins, TO, no mês de outubro de 2013. Os frutos foram colhidos ao chão quando sua casca se apresentava de cor marrom escura e pequenos sinais de rachadura, indicando estágio adequado de maturação, posteriormente acondicionados em caixas plásticas e transportados para a Unidade de Processamento.

Para o processamento da geleia tomou-se como base a metodologia descrita por Jackix ${ }^{19}$ adaptada, conforme a Figura 1.

Inicialmente as frutas foram higienizadas em água corrente para retirar algum resíduo presente, em seguida, foram descascadas manualmente e lavadas em solução de água clorada 5 ppm. Após a higienização, a matéria-prima foi mantida em repouso por cerca de 20 minutos com água para facilitar o seu despolpamento.

A polpa obtida por meio de uma despolpadora industrial em aço inoxidável foi acondicionada em sacos plásticos de polietileno e embalada a vácuo para ser armazenada em freezer a -18 으 até o momento do processamento.

Formularam-se dois tipos de geleia de tamarindo, mantendo as quantidades constantes de seus ingredientes básicos açúcar, água e ácido, variando o conteúdo em pectina, sendo uma das formulações sem pectina e a outra com adição de solução de pectina extraída do albedo do maracujá amarelo (Passiflora edulis), não sendo necessária a adição de ácido nas formulações.

Foram utilizados maracujás maduros adquiridos no comércio local da Cidade de Paraíso do Tocantins-TO para obtenção da solução de pectina. A extração da pectina baseou-se na metodologia descrita por Lira Filho e Jackix..$^{20}$ Lavouse os frutos com água corrente e detergente neutro, deixou-os por 30 minutos em solução de cloro a 100 ppm, descascou-se, retirando-se a película amarela da casca, cortou-se ao meio para retirada da polpa, picou-se o albedo manualmente, transferiu-se para um liquidificador na proporção 1:3 (albedo/água) e triturou-se até se obter uma massa homogênea. Após, adicionou-se $5 \mathrm{~mL}$ de suco de limão e realizouse cocção em temperatura branda até obtenção de um gel uniforme, em seguida esfriou-se, filtrou-se e acondicionou-se em frascos de vidro previamente 


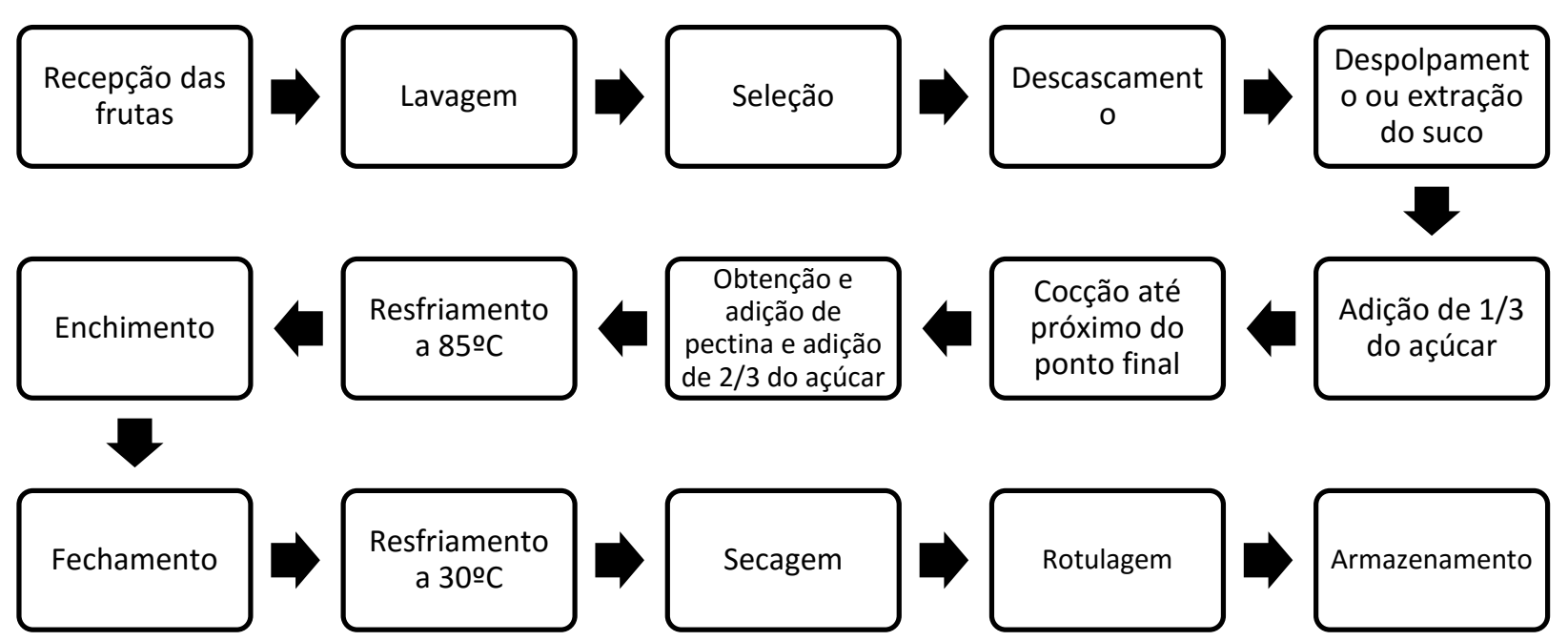

Figura 1.Fluxograma do processamento da geleia em tacho aberto (Fonte: JACKIX ${ }^{19}$ ).

Figure 1. Processing flowchart jelly in pot open (Source: JACKIX ${ }^{19}$ ).

esterilizados, armazenando-se em geladeira para ser utilizado na geleia. A geleia de tamarindo foi formulada inicialmente com $3 \mathrm{~kg}$ de polpa de tamarindo, $2 \mathrm{~kg}$ de açúcar (1/3 do total) e 2,4 Kg de água concentrando em tacho aberto a temperatura de $95 \circ C$ até próximo de 60Brix, quando se adicionou o restante do açúcar $60 \mathrm{~g}$ de pectina extraída do albedo do maracujá amarelo, equivalente a $2 \%$ do peso da polpa e prosseguiu $o$ aquecimento até a temperatura de $105^{\circ} \mathrm{C}$.

O processamento foi interrompido quando a geleia atingiu $65^{\circ}$ Brix, medido com auxílio de refratômetro de bancada. Resfriou-se a temperatura de $85^{\circ} \mathrm{C}$ e realizou-se o enchimento a quente. Reduziu-se em seguida a temperatura da geleia a 30 ㄷ C sob água corrente, efetuando-se a troca da água quente pela água fria. Finalmente, após o produto ter sido seco e rotulado permaneceu armazenado em estufa a $35^{\circ} \mathrm{C}$ por período de 15 dias para verificar se houve vazamento, estufamento ou mesmo crescimento de microrganismos mesófilos. Decorrido este tempo, foram retiradas amostras para realização das análises físico-químicas, microbiológicas e sensorial. Na segunda formulação mantiveram-se os mesmos passos sem adicionar a pectina.

\section{B) Delineamento experimental e análise estatística}

Foi utilizado o delineamento inteiramente casualizado para as análises químicas e microbiológicas com três repetições. Para a análise sensorial, utilizou-se o delineamento em blocos casualizados, sendo os blocos representados pelos julgadores.

Os resultados foram avaliados estatisticamente através de análise de variância. Quando constatada a significância pelo teste $F$, os tratamentos foram comparados pelo teste de Tukey para as características físico-químicas e microbiológicas, ambos ao nível de $5 \%$ de probabilidade. As análises foram realizadas com auxílio do programa computacional XLSTAT versão7.5.2. ${ }^{21}$

\section{C) Características físico-químicas}

As características físico-químicas realizadas foram pH, Acidez Total Titulável (ATT), Sólidos Solúveis Totais (SST), SST/ATT, Cinzas e Umidade.

O potencial hidrogeniônico $(\mathrm{pH})$ foi medido diluindo-se $10 \mathrm{~g}$ da amostra em $100 \mathrm{~mL}$ de água destilada, utilizando-se um potenciômetro digital 
(modelo mPA-210, marca tecnopon), com membrana de vidro, conforme Instituto Adolfo Lutz $(\mathrm{IAL})^{22}$, aferido com tampões de $\mathrm{pH} 7$ e 4.

Obteve-se a acidez total titulável diluindo-se de 1 a $4 \mathrm{~g}$ de amostra em $50 \mathrm{~mL}$ de água destilada em um titulador potenciométrico (modelo mPA210, marca tecnopon) até $\mathrm{pH} 8,3$ com solução de $\mathrm{NaOH}(0,1 \mathrm{M})$ e expressa em percentagem de ácido cítrico, segundo metodologia do IAL. ${ }^{22}$

De acordo com a metodologia recomendada pela $A O A C^{23}$, após filtração da amostra em papel de filtro, efetuou-se a leitura (Вrix) em um refratômetro de bancada Abbé (modelo ref. 103) com escala variando de 0-90Brix, devidamente calibrado e ajustado a 20 ㅇ C com água destilada. Os valores de oBrix foram corrigidos quando a temperatura era diferente dos $20^{\circ} \mathrm{C}$.

A determinação do resíduo mineral fixo (cinzas) foi efetuado pesando-se $10 \mathrm{~g}$ de amostras nos cadinhos de porcelana, submeteu-se a aquecimento brando e gradativo para a carbonização parcial do material através de bico de Bunsen. Posteriormente as amostras foram colocadas na mufla com temperatura de $550^{\circ} \mathrm{C}$ durante $10 \mathrm{~h}$ e em seguida procedeu-se aos cálculos. $^{16}$

O teor de umidade foi obtido através do método de estufa onde a amostra foi pesada e mantida em temperatura de 105으 por 1 hora, resfriada em dessecador e pesada novamente. Este procedimento foi realizado até obter-se peso constante. ${ }^{16}$

\section{D) Análises microbiológicas}

As análises foram desenvolvidas através da metodologia descrita por Silva et al. ${ }^{24}$

\section{E) Análise sensorial}

A análise sensorial foi realizada por provadores não treinados, que foram selecionados de forma aleatória (diferente idade e sexo). Entre eles, 60 avaliadores (docentes, discentes, técnicos administrativos e terceirizados) do Instituto Federal de Educação, Ciência e Tecnologia do Tocantins Campus Paraíso do Tocantins, sendo 35 do sexo feminino e 25 do sexo masculino, com idade entre 14 e 50 anos. O procedimento ocorreu em
Laboratório de Análise sensorial, com cabines individuais.

As amostras de geleia foram apresentadas aos provadores em copos plásticos de $50 \mathrm{~mL}$ codificados com algarismos de 4 dígitos aleatórios para não induzir ao erro lógico. Estas foram servidas com $5 \mathrm{~g}$ aproximadamente e como veículo de acompanhamento utilizou-se bolacha tipo água e sal e um copo de $100 \mathrm{~mL}$ com água para limpeza do palato entre a avaliação das amostras. Os atributos avaliados foram: cor, aparência, consistência, odor, sabor e aceitação global. Para o teste de aceitação cada provador recebeu uma ficha de avaliação sensorial, com escala hedônica estruturada de nove pontos, abrangendo de "desgostei muitíssimo" a "gostei muitíssimo". ${ }^{25}$

O provador também respondeu qual a amostra de sua preferência e qual compraria. E como informação complementar respondeu qual sua frequência e razão de consumo de acordo com a Figura 2.

Os resultados no que diz respeito à frequência de consumo e à intenção de compra para cada uma das amostras do produto processado foram anotados em porcentagem em relação ao número total de pessoas consultadas. Para verificar a aceitação dos produtos, foi realizado o cálculo do índice de aceitabilidade (IA), utilizando-se a equação abaixo:

$$
I A=100 \times \frac{\text { Média }}{\text { MaiorNota }} \quad \text { Eq. (1) }
$$

Onde: Média = representa nota média na escala hedônica, obtida para o produto analisado e Maior nota $=$ representa a nota máxima na escala hedônica que o produto recebeu. $70 \% .^{26,27}$

O IA considerado de boa repercussão é $\geq$

\section{RESULTADOS E DISCUSSÃO}

\section{A) Características físico-químicas e microbiológicas}

Os resultados das características físicoquímicas e microbiológicas das duas formulações de geleia de alto teor de tamarindo foram obtidos pela média das 3 repetições de cada variável estudada e 


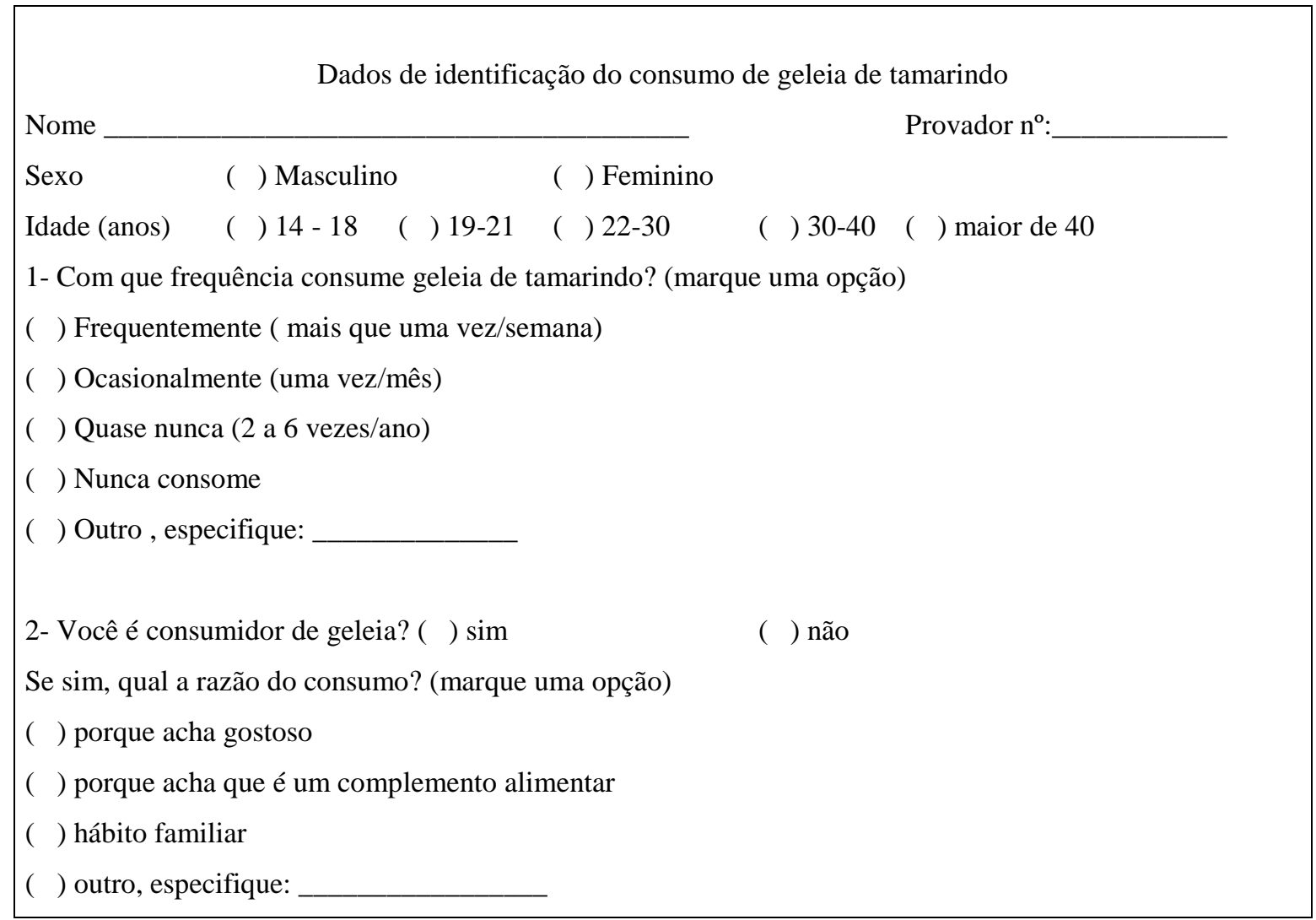

Figura 2. Ficha utilizada para obter informações complementares da geleia de tamarindo.

Figure 2.Form used to obtain additional information from the tamarind jam.

encontram-se na Tabela 1.

A quantidade de sólidos solúveis totais da geleia com pectina adicionada do albedo do maracujá foi de 65,11 @Brix (Tabela 1), indicando que a formulação realizada foi precisa, pois o valor encontrado está dentro dos parâmetros estabelecidos pela Resolução - CNNPA no 12 que deve conter mínimo de 65ㅂix. Enquanto o produto obtido sem pectina apresentou resultado inferior ao desta resolução, 63,47으rix. Se observado o teor de água obtido pela determinação de umidade, verifica-se que a geleia com pectina adicionada possui maior valor, porém não diferiu estatisticamente da amostra com pectina natural da fruta. O teor de sólidos solúveis é de fundamental importância para consumo in natura como para indústria, pois ela está relacionada principalmente com o sabor do fruto que inclui os açúcares e ácidos. Esta variável também influencia o rendimento industrial, especialmente o peso final do produto processado. ${ }^{28}$

O conteúdo de umidade foi mais expressivo na geleia com pectina adicionada do albedo do maracujá do que na geleia sem pectina. Segundo Taco $^{29}$ o teor de umidade para o fruto tamarindo cru é de $22 \%$. Na elaboração da geleia alguns pontos podem aumentar a sua umidade: 1) na obtenção da polpa do tamarindo em que houve a necessidade de adicionar água para facilitar o despolpamento; 2 ) na formulação da geleia em que se adicionou 2,4 $\mathrm{Kg}$ de água e 3) na adição da pectina como solução pectina e água.

Além disso, Jackix ${ }^{19}$ aponta vários fatores que podem contribuir para má formação de gel e sinérese, tais como, acidez excessiva $(\mathrm{pH}$ muito baixo), baixo teor de sólidos solúveis, deficiência de pectina.

O conteúdo de água é um parâmetro de qualidade muito importante em praticamente todos os produtos alimentícios, bem como em seus ingredientes, senão for uma influência decisiva na qualidade e especialmente na vida de prateleira de praticamente todo material de origem. ${ }^{30}$

$\mathrm{O} \mathrm{pH}$ das duas geleias de tamarindo indica um valor característico de uma fruta muito ácida, 
Tabela 1.Resultado das características físico-químicas e microbiológicas das geleias de alto teor de tamarindo.

Table 1. Results of physicochemical and microbiological characteristics of high content tamarind fruit jellies.

\begin{tabular}{lcc}
\hline & \multicolumn{2}{c}{ Tratamentos } \\
\cline { 2 - 3 } Características & Sem & $\begin{array}{c}\text { Com } \\
\text { pectina }\end{array}$ \\
\hline \multicolumn{2}{c}{ Características Físico-Químicas } \\
\hline${ }^{\circ}$ Brix & $63,47 \mathrm{~b} \pm 0,05$ & $65,11 \mathrm{a} \pm 0,16$ \\
Umidade (\%) & $33,94 \mathrm{a} \pm 0,79$ & $38,88 \mathrm{a} \pm 4,13$ \\
$\mathrm{pH}$ & $2,92 \mathrm{a} \pm 0,09$ & $3,01 \mathrm{a} \pm 0,01$ \\
Acidez (\%) & $1,91 \mathrm{a} \pm 0,06$ & $1,82 \mathrm{a} \pm 0,02$ \\
SST/ATT & $33,28 \mathrm{~b} \pm 1,05$ & $35,79 \mathrm{a} \pm 0,31$ \\
Cinzas (\%) & $0,51 \mathrm{~b} \pm 0,12$ & $0,98 \mathrm{a} \pm 0,19$ \\
\hline & Análises microbiológicas \\
\hline Bolores e leveduras (UFC/g) & $880,00 \mathrm{a} \pm 995$ & $676,67 \mathrm{a} \pm 421$ \\
\hline
\end{tabular}

Média de três repetições seguidas de desvio padrão. Letras diferentes dentro da mesma linha indicam diferenças estatísticas de acordo com teste de Tukey $(p<0,05)$.

Average of three replications followed by standard deviation. Different lowercase letters in the same row indicate significant differences according to Tukey's test $(p<0.05)$.

não havendo necessidade de adição de acidulantes, implicando em menores custos para a empresa e do ponto de vista de segurança alimentar, produtos com pH inferior a 4,5 inibe a ação do Clostridium botulinum, microrganismo patogênico anaeróbio, causador do botulismo.

Todavia, quanto ao aspecto tecnológico, este valor está abaixo do padrão de 3,2 para processamento de geleia de acordo com Jackix, ${ }^{19} \mathrm{e}$ que segundo Lovatel, Constanzi e Capelli ${ }^{31}$ valores inferiores podem resultar em gel fraco comprometendo a qualidade do produto final.

A acidez total titulável de modo geral serve para medir o sabor ácido ou azedo de frutos, representada pela quantidade de ácidos orgânicos na amostra, neste caso, com maior predominância o tartárico, mas também indica o estádio de maturação e decomposição dos frutos, este último ocasionado pela ação de bactérias fermentativas. ${ }^{1} \mathrm{~A}$ geleia que mostrou maior conteúdo em ácido $(1,91 \%)$ foi a sem pectina que pode ser confirmada pela análise de $\mathrm{pH}$ que também revelou valor mais ácido $(2,92)$.

A característica SST/ATT é uma das melhores formas de avaliação do sabor dos frutos, devido ao balanço de ácidos e açúcares. ${ }^{32,33}$ A geleia sem pectina apresentou relação de $(63,47 / 1,91)$, enquanto a geleia com pectina adicionada do albedo do maracujá $(65,11 / 1,82)$. O maior valor $(35,79)$ foi revelado na geleia com a maior concentração de açúcar, uma vez que foi esta geleia que apresentou o menor valor de acidez total. Barcia et al. ${ }^{34}$ encontraram em geleias de jambolão valores bem inferiores $(6,21$ a 6,78), o que está relacionada à elevada acidez encontrada nas geleias pelos autores. Para o mercado consumidor de frutas frescas e/ou processadas, a relação elevada é desejável. ${ }^{35}$ Uma relação elevada traduz-se em doçura o que evidencia um sabor mais agradável. ${ }^{36}$

O conteúdo de cinzas foi maior na geleia com pectina adicionada $0,98 \%$, e menor na geleias em pectina $0,51 \%$. Sabendo-se que os minerais concentram-se nas cascas dos vegetais e que a pectina foi obtida do albedo do maracujá através de um método artesanal, isso explica a diferença do aumento entre uma amostra e outra. No entanto, ambas as geleias mostraram valores inferiores aos encontrados por $\operatorname{Taco}^{29}$ na análise de frutos crus em $100 \mathrm{~g}$ da amostra, que foi $1,9 \%$. Segundo Mahan e Escott-Stump ${ }^{37}$, as cinzas/minerais são benéficas ao organismo, pois funcionam como reguladores responsáveis pela constituição e ação de enzimas e hormônios, além de funções estruturais.

\section{B) Análises microbiológicas}

A avaliação microbiológica da geleia de tamarindo resumiu-se a pesquisa de bolores e leveduras, devido as suas características físicoquímicas, como baixo $\mathrm{pH}$, altos conteúdos de açúcares, que limitam o crescimento de bactérias 
patogênicas. Mesmo que estas últimas desenvolvam-se por poucas horas ou poucos dias, sua população diminui significativamente, predominando os microrganismos deteriorantes como os bolores, leveduras e bactérias ácidotolerantes. $^{38}$

Segundo a Resolução RDC no. $12^{39}$, de 02 de janeiro de 2001 é preconizado tolerância de 104 bolores e leveduras para cada $1 \mathrm{~g}$ de frutas, produtos de frutas e similares, tais como purês e doces em pasta ou massa, incluindo geleias, não comercialmente estéreis. As amostras analisadas apresentaram média de 778,5 UFC de bolores e leveduras/g, sendo que a geleia com pectina adicionada apresentou maior valor 880 UFC de bolores e leveduras/g e a geleia sem pectina menor valor 677 UFC de bolores e leveduras/g.

Mesmo a geleia sendo um produto que oferece boas condições e nutrientes para o desenvolvimento destes microrganismos, os resultados revelados mostra que as duas formulações estão dentro dos padrões estabelecidos pela legislação, sem comprometer a qualidade e segurança alimentar.

\section{C) Análise sensorial}

Não houve diferença significativa entre as formulações de geleia quanto aos atributos de cor, aparência, consistência, odor, sabor e aceitação global ( $p>0,05$ ) (Tabela 2). Os atributos sensoriais para as geleias sem pectina e com pectina adicionada do albedo de maracujá apresentaram boa aceitação, com escores variando de 7,63 a 9,28, ou seja, entre os termos hedônicos "gostei moderadamente" e "gostei extremamente". Destaca-se que os atributos com as melhores médias de aceitação foram o atributo cor $(9,06)$ e sabor $(9,28)$.

\section{D) Frequências de consumo e intenção de compra}

Quanto à frequência de consumo de geleia (Figura 3), identificou-se que 43,33\% dos julgadores quase nunca o fazem, $20 \%$ o fazem ocasionalmente, $18,33 \%$ regularmente e $16,67 \%$ nunca consomem este tipo de produto. Quando perguntados sobre por que você é consumidor de geleia de tamarindo, $33,33 \%$ responderam por achar gostoso, $16,67 \%$ consomem como complemento a alimentação diária, $10 \%$ por hábito familiar e $40 \%$ responderam não ter o costume de consumir este produto.

Com relação à intenção de compra (Figura 4) da geleia de tamarindo verificou-se que as amostras apresentadas foram bem aceitas pelos julgadores, uma vez que a maioria atribuiu notas entre 4 e 5 , correspondentes a "provavelmente compraria" e "certamente compraria".

Tais resultados corroboram os obtidos na avaliação da cor e aparência, cujo atributo comportou-se de maneira semelhante entre os tratamentos e cujas notas se mantiveram acima do limite de aceitabilidade ( $>5)$. De acordo com Deliza ${ }^{40}$ e Modesta ${ }^{41}$, o aspecto visual do produto é determinante na aquisição do mesmo pelo consumidor. Qualquer alteração neste atributo pode diminuir sua aceitabilidade.

Ambas as formulações apresentaram boa aceitabilidade com $\mathrm{IA}(\%)$ maior que $70 \%$, limite proposto por Teixeira et al. $^{26}$ e Dutcosky ${ }^{27}$ no quesito de aceitabilidade. De acordo com Correia et al. $^{42}$, a aceitabilidade representa o principal ponto crítico na elaboração de novos produtos para o mercado.

Tabela 2. Médias dos atributos de cor, aparência, consistência, odor, sabor e aceitação global das geleias.

Table 2.Averages of the attributes of color, appearance, consistency, smell, taste and global acceptance of jellies.

\begin{tabular}{ccccccc}
\hline Amostra & Cor & Aparência & Consistência & Odor & Sabor & $\begin{array}{c}\text { Aceitação } \\
\text { global }\end{array}$ \\
\hline $\begin{array}{c}\text { Sem pectina } \\
\text { Com pectina } \\
\text { de maracujá }\end{array}$ & $9,06 \mathrm{a} \pm 1,02$ & $8,88 \mathrm{a} \pm 1,16$ & $8,28 \mathrm{a} \pm 0,86$ & $8,91 \mathrm{a} \pm 1,44$ & $9,28 \mathrm{a} \pm 1,05$ & $7,86 \mathrm{a} \pm 1,03$ \\
\end{tabular}

Médias seguidas da mesma letra na coluna não apresentam diferença $(p>0,05)$ pelo teste de Tukey.

Average followed by the same in the column lowercase letter not difference $(p>0.05)$ by Tukey test. 


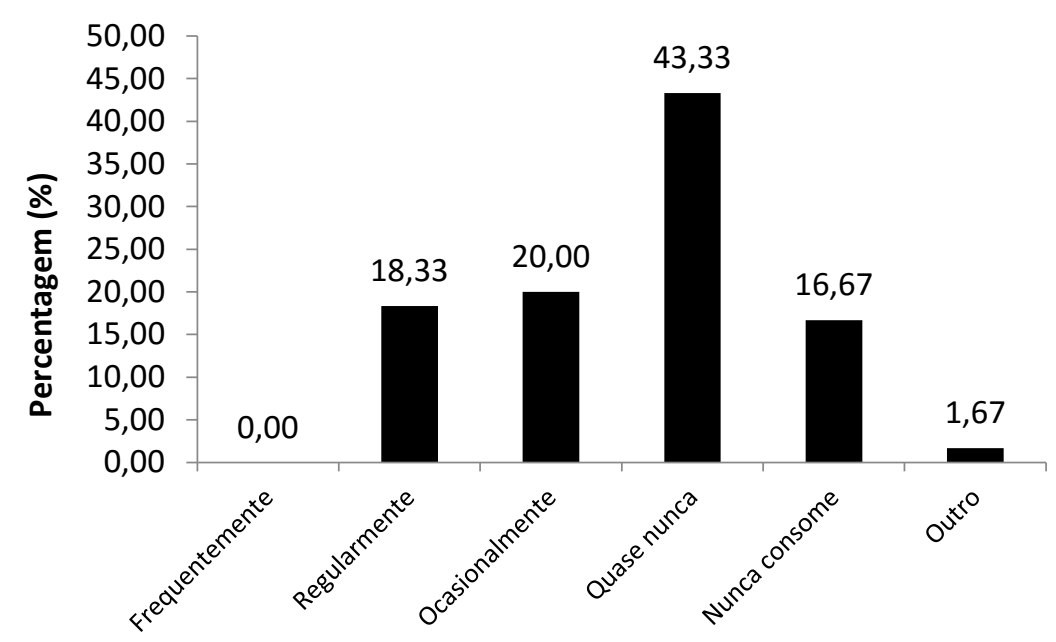

Figura 3. Frequência de consumo

Figure 3. Frequencyjelly consumption

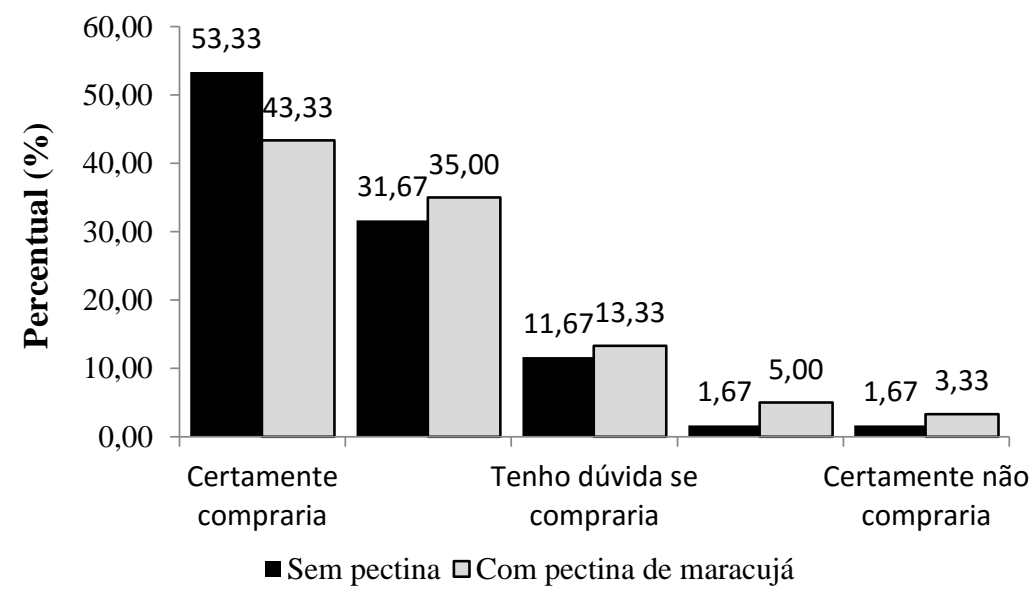

Figura 4. Resultados para a intenção de compra da geleia de tamarindo.

Figure 4. Results for the purchase intent of tamarind jam

$\mathrm{Na}$ avaliação da preferência, $50 \%$ dos provadores preferiram a geleia sem pectina, $42 \%$ dos provadores preferiram a geleia com pectina e $8 \%$ responderam "nenhuma".

\section{CONCLUSÃO}

As duas formulações de geleias apresentaram características físico-químicas e microbiológicas dentro dos padrões estabelecidos pela legislação vigente do país. Os produtos analisados apresentaram índice de aceitação para os atributos analisados superiores a $80 \%$ e intenção de compra, apesar de apenas $18,33 \%$ dos provadores ter declarado que consomem regularmente geleias. Os maiores índices de aceitabilidade foram para geleia sem pectina.

\section{CONTIBUIÇÃO DOS AUTORES}

\section{Desenvolvimento e condução do experimento; Elaboração do artigo científico.}

Florisvaldo Gama de Souza

\section{Orientação, avaliação, revisão e elaboração do artigo}

Fabrízio da Fonseca Barbosa (D) e Fernando Morais Rodrigues iD 


\section{REFERÊNCIAS BIBLIOGRÁFICAS}

1. HAMACEK, F. et al. Tamarindo do cerrado mineiro: caracterização física, físico-química, carotenóides e vitaminas. Nutrire, v.36, Sup, p.69-69, 2011.

2. DONADIO, L.C.; NACHTIGAL, J.C.; SACRAMENTO, C.K. do. Frutas exóticas. Jaboticabal: FUNEP, 1988, 279p.

3. URSZULA, T.; LÓPEZ, J.F.; ÁlVAREZ, J.A.P.; MARTOS, M.V. Chemical, physicochemical, technological, antibacterial and antioxidant properties of rich-fibre powder extract obtained from tamarind (Tamarindus indica L.). Industrial Crops and Products, v.55, p.155162, 2014. Crossref

4. IZZO, A.A.; CARLO, G.D.I; BORRELLI, F.; ERNST, E. Cardiovascular pharmacotherapy and herbal medicines: the risk of drug interaction. International Journal of Cardiology, v.98, n.1, p.1-14, 2005. Publimed

5. HAVINGA, R.M.; HARTL, A.; PUTSCHER, J.; PREHSLER, S.; BUCHMANN, C.; VOGL, C.R. Tamarindus indica $L$. (Fabaceae): Patterns of use in traditional African medicine. Journal of Ethnopharmacology. v.127, n.3, p.573-588, 2010. Crossref

6. GURJÃO, K.C.O. Desenvolvimento, armazenamento e secagem de tamarindo (Tamarindus indica L.). 2006. 145f. Tese (Doutorado em Agronomia) - Centro de Ciências Agrárias, Universidade Federal da Paraíba, Areia-PB, 2006.

7. FERREIRA, E.A.; MENDONÇA, V.; SOUZA, H.A. de; RAMOS, J.D. Adubação fosfatada e potássica na formação de mudas de tamarindeiro. Scientia Agrária, v.9, n.4, p.475-480, 2008.

8. KOPF, C., Técnicas de processamento de frutas para a agricultura familiar. 2008. Disponível em: <www.unicentro.br/editora/livros/2008/frutas.pdf>. Acesso: em nov. de 2012.

9. COSTA, E. et al. Diferentes composições de substratos e ambientes protegidos na formação de mudas de péfranco de tamarindeiro. Revista Brasileira de Fruticultura, v.34, n.4, 2012. Crossref

10. BRASIL. Resolução CNS, Resolução Normativa $\mathbf{N}^{\circ}$ 15, de 1978. Define termos sobre geleia de frutas. Diário Oficial da União, Brasília, de 11 de dezembro de 1978.

11. BRASIL. Resolução ANVISA/MS. RDC N²72 de $\mathbf{2 2}$ de setembro de 2005. Aprova o regulamento técnico para produtos de vegetais, produtos de frutas e cogumelos comestíveis. Diário Oficial da União, Brasília, de 23 de setembro de 2005.

12. BRASIL. Resolução ANVISA/MS. RDC №. 45, de 03 de novembro de 2010. Dispõe sobre aditivos alimentares autorizados para uso segundo as Boas Práticas de Fabricação (BPF). Diário Oficial da União, Brasília, de 05 de novembro de 2010.

13. ABREU, M.C.; NUNES, I.F.S.; OLIVEIRA, M.M.A. Perfil microbiológico de polpas de frutas comercializadas em Teresina, PI. Higiene Alimentar, v.17, n.112, p. 78-81, 2003.

14. VENDRUSCOLO, C.T; MOREIRA, A. da S.; SILVA, J. L. da. Tecnologia de Frutas e Hortaliças: geleias, doces cremosos e em massa. 2.ed. rev. Pelotas: Ed. Universitária da UFPEL, 2012.

15. FRANCO, B. D. G. M.; LANDGRAF, M. Microbiologia dos Alimentos. São Paulo, Ed. Atheneu, 2007. p27-171.

16. GOMES, J. C.; OLIVEIRA, G. F. Análises físicoquímicas de alimentos. Viçosa- MG: Ed. UFV, 2012. $3030 \mathrm{p}$.

17. ANZALDÚA-MORALES A. La evaluación sensorial de los alimentos en la teoría y lapráctica. Zaragoza: Acribia, 1994. 198p.

18. FERREIRA, V.L.P.; ALMEIDA, T.C.A.; PETTINELLI, M.L.C.V.; SILVA, M.A.A.P.; CHAVES, J.B.P.; BARBOSA, E.M.M. Análise sensorial: testes discriminativos e afetivos. manual: série qualidade. Campinas, SBCTA, 2000. 127p.

19. JACKIX, M.H. Doces, geleias e frutas em calda. Campinas: Unicamp. São Paulo: Ícone. 1988.

20. LIRA FILHO, J.de; JACKIX, M. de N.H. Utilização da casca do maracujá-amarelo ( $P$. edulisf. Flavicarpa, Degener) na produção de geléia. Fortaleza : EMBRAPACNPAT, 1996. 23p. (EMBRAP A-CNPAT, Boletim de Pesquisa, 17).

21. ADDINSOFT: XIstat supplement. Versão 7.5.2 para Excel 2010. Reino Unido: Addinsoft 2015.

22. INSTITUTO ADOLF LUTZ. Normas Analíticas do Instituto Adolf Lutz. v.1: Métodos químicos e físicos para análise de alimentos; 3ạ Ed. São Paulo: IMESP, 2005. 
23. AOAC. Association of Official Analytical Chemists. Official Methods of Analysis of AOAC International. 17th. v. II., 2000.

24. SILVA, N. da et al. Manual de métodos de análise microbiológica de alimentos. São Paulo: Livraria Varela, 536p. 2007.

25. STONE, H.S.; SIDEL, J.L. Sensory Evaluation Practices. Academic Press, San Diego, CA. 1993, 308p.

26. TEIXEIRA, E.; MEINERT, E.M.; BARBETTA, P.A. Métodos sensoriais. In: Análise sensorial de alimentos. Florianópolis, Editora da UFSC, 1987. p. 66-119.

27. DUTCOSKY, Silvia Deboni. Análise sensorial de alimentos. Champagnat, 2011.

28. MACÊDO, L. de S.; ARAÚJO, I.A. de; FRANCO, C.F. de O. Caracterização físico-química de frutos da mangabeira nativa e naturalizada da Mata Paraibana. In: SIMPÓSIO BRASILEIRO SOBRE A CULTURA DA MANGABA, 2003, Aracajú. Anais... Aracajú: Embrapa Tabuleiros Costeiros, 2003. 1 CD.

29. TACO. Tabela brasileira de composição de alimentos / NEPA - UNICAMP. 4. ed. rev. e ampl. Campinas: NEPAUNICAMP, 2011. 161 p. Disponível em: <http://www.unicamp.br/nepa/taco/contar/taco 4 e dicao_ampliada_e revisada.pdf?arquivo=taco 4 versa o ampliada e revisada.pdf>. Acesso em: 02 abr. 2013.

30. ABRAMOVIC, H.; JAMNIK, M.; BURKAN, L.; KAC, M. Water Activity and Water Content in Slovenian Honeys. Food Control, v.19, n.11, p. 1086-1090, 2008. Crossref

31 LOVATEL, J.L.; CONSTANZI, A.R; CAPELLI, R. Processamento de frutas e hortaliças. Caxias do Sul RS: Educs, 2004. 189 p.

32. CHITARRA, A.B.; CHITARRA, M.I.F. Pós-colheita de frutos e hortaliças: fisiologia e manuseio. Lavras: ESAL/FAEPE, 1990, 293p.

33. GONÇALVES, N.B.; CARVALHO, V.D. de; GONÇALVES, J.R. de A.; COELHO, S.R.M.; SILVA, T. das G. Caracterização física e química dos frutos de cultivares de mangueira (Mangifera indica L.). Ciência e Agrotecnologia, v.22, n.1, p.72-78, 1998.

34. BARCIA, M.T.; MEDINA, A.L.; ZAMBIAZI, R.C. Características físico-químicas e sensoriais de geleias de jambolão. Boletim do Centro de Pesquisa de Processamento de Alimentos, v.28, n.1, p.25-36, 2010.

$\checkmark$ Crossref

35. AGUIAR, L.P. Qualidade e potencial de utilização de bacuris oriundos da região Meio-Norte. Fortaleza, 2006, 122f. Dissertação (Mestrado em Tecnologia de Alimentos) - Universidade Federal do Ceará, Fortaleza, Ceará, 2006.

36. COSTA, L. Qualidade pós-colheita de citros. Informe Agropecuário, Belo Horizonte, v.17, n.80, p.45-51, 1994.

37. MAHAN, L.K.; ESCOTT-STUMP, S. Krause: alimentos, nutrição e dietoterapia. 12. ed. São Paulo: Roca, 2010.

38. MAIA, G.A.; SOUZA, P.H.M. de; LIMA, A. da S. Processamento de sucos de frutas tropicais. Fortaleza: Edições UFC, 2007.

39. BRASIL. ANVISA. Agência Nacional de Vigilância Sanitária. Resolução RDC no. 12, de 02 de janeiro de 2001. Regulamento Técnico sobre padrões microbiológicos para alimentos, publicada no Diário Oficial da União, Brasília, DF, 10 de janeiro de 2001, seção 1, p. 45 a 53.

40. DELIZA, R. Importância da qualidade sensorial em produtos minimamente processados. In: ENCONTRO NACIONAL SOBRE PROCESSAMENTO MÍNIMO DE FRUTAS E HORTALIÇAS, 2., 2000, Viçosa. Palestras. Viçosa: UFV, 2000. p. 73-74.

41. MODESTA, R.C.D. Manual de análise sensorial de alimentos e bebidas. Rio de Janeiro: EMBRAPA-CTAA, 1994. $67 \mathrm{p}$

42. CORREIA, R.T.P.; Mendonça, S.C.; Lima, M.L.; Silva, P.D. Avaliação química e sensorial de linguiças de pescado tipo frescal. Boletim do Centro de Pesquisa de Processamento de Alimentos, v.19, n.2, p.183-189, 2001. Crossref 